\title{
A prospective study to find out the most cost effective preoperative prophylactic antibiotic regime in elective abdominal routine surgeries
}

\author{
Ganguly NN ${ }^{1}$, Ray RP ${ }^{2}$, Lahkar $M^{3}$, Siddiqui $\mathrm{A}^{4}$ \\ ${ }^{1}$ Dr. Narendra N Ganguly, Associate Professor of Surgery, ${ }^{2}$ Dr. Rituparna Phukan Ray, Associate Professor of \\ Pharmacology, ${ }^{3}$ Dr. M Lahka, Professor of Pharmacology, GMCH, ${ }^{4}$ Ms Aisha Siddiqui, M.Pharm Scholar, NEIPER, \\ JMCH, Jorhat, Assam, India.
}

Address for Correspondence: Dr. Narendra N Ganguly, Email: drganguly@yahoo.com

\begin{abstract}
Introduction: Anti microbial prophylaxis before any elective surgery is a preferred deterrent to post operative surgical site infection now. A study was undertaken to evaluate the efficacy of preoperative prophylaxis in our hospital setting. We have used different antibiotics, two being from the cephalosporin class, one from the fluoroqiuinolones and anti beta lactamases in combination along with metronidazole. These were used in different combinations and for different durations. The aim was to find out the best and most economical pre operative prophylaxis in our surgical practice. Methods: A total of 138 patients (above 16 years) were taken for the study. It was a randomized and blind study. Patients were prospectively analysed. First, the patients were divided into two groups, those who would receive a single dose of antibiotic at incision and those who received two more doses after the dose at incision. Next, the patients were analysed depending on operation room condition wise. The open elective as well as the laparoscopic elective procedures done in an OT condition where emergencies are undertaken as well as open and lap cases done in OTs where only elective cases are undertaken. The routine practice of preoperative bath, preoperative preparations of the area with iodophores and spirit, operating under normothermia and hydration were as per the institutional philosophy and common to all the patients. Cefotaxime+ Sulbactum, Ofloxacin + Metronidazole, Cefepime+ Tazobactum. Result: Keeping the outcome of the study in mind all the materials was analysed and statistical analysis done and confidence intervals were noted. The single dose pre operative prophylaxis scored over three doses regime in all the cases for lap surgery irrespective of OT condition. Three doses regime worked better in combined OT condition for the open elective procedures. The study also revealed the most economic choice for routine elective abdominal surgery. Conclusion: Multiday and antibiotics use for a prolonged period is not advisable these days after a routine elective abdominal surgery. Single dose injection of antibiotics at a proper time is good enough for preventing postoperative surgical site infection after a routine Laparoscopic surgery. Three doses regime is better in open surgical cases performed in OTs where emergency procedures are undertaken. It is advisable to use the most cost effective regime to reduce the healthcare cost in the country.
\end{abstract}

Key Words: Postoperative, Surgical site infections, Antibiotics.

\section{Introduction}

All though modern surgery started in the seventeenth century; it really progressed after the advent of anesthesia and the concept of sepsis. It was Joseph Lister who revolutionized the infection free practice of surgery by his understanding of germs and spraying Phenol in and around the operating environment. The

Manuscript received: $4^{\text {th }}$ Jan 2016

Reviewed: $14^{\text {st }}$ Jan 2016

Author Corrected: $4^{\text {th }} \mathrm{Feb} 2016$

Accepted for Publication: 14 ${ }^{\text {th }}$ Feb 2016 days of Laudable Pus were finally over. He is aptly recognized as the father of modern surgery [1].

However surgical site infections still worry the surgeons and many methods are in place to prevent it. The rate is stabilized at $2 \%$ foe extra abdominal surgeries and over $20 \%$ for intra abdominal procedures [2]. 
Surgical site infection or SSI is defined by the centre for disease control and prevention, Atlanta, as a proliferation of micro-organism in the incision site either within the skin ad subcutaneous tissue, muskulofascial layers, or in an organ and a cavity [3].

The CDC also has a recommended guideline for antimicrobial prophylaxis $[4,5]$.

1. To use AMP in those procedures, which carry a risk of infection,when the consequences of such infection is great and have evidence that using AMP reducing the incidence of SSIs.

2. To select an agent which is safe, inexpensive, preferably bactericidal and most narrowly covers the anticipated SSI in that particular procedure.

3. Time the administration so that it reaches the maximum serum and tissue concentration at the time of incision.

4. Maintain adequate level/ therapeutic level of the antibiotics at the closure of the incision.

There is widespread evidence of using AMP before all surgical procedures that is it is beneficial and prevent SSIs $(6,7)$.

A meta-analysis on AMP in biliary surgery suggests that increase of SSIs over 9 times if compared to those cases where no AMP was use with $95 \%$ confidence Interval [8]. Single dose cephalosporins was found to be effective in Biliary, genitor-urinary and gynaecological procedures was found to be efficacious in preventing SSIs in these procedures [9]. It is well established that Prophylactic antibiotics must be injected at anaesthesia and it has been shown that multiple doses regime is redundant for preventing SSI. It is also shown that antibiotics given over two hours preoperatively failed to initiate desired effect and action.

Keeping these factors in mind the study was undertaken to evaluate the best and most economic prophylactic antibiotics regime in two different environments. One, in which both emergency as well as elective abdominal cases are undertaken, the second is where only elective cases are undertaken. The reason being, such conditions exist in the state of Assam. Both laparoscopic as well as open elective cases were considered $t$ find out if any difference would come out after the study.

\section{Materials and Methods}

A total of 138 patients were taken for the study. Inclusion criteria were above 16 years of age and no history of allergy to cephalosporins, imidazoline derivatives, beta lactamase inhibitors, fluoroxoquinolones and history of seizures. Excluded are the emergency procedures and history of seizures and hypersensitivity towards the chemicals to be used.

The patients were divided into the study groups in a randomized and blinded method. Cheat picking was applied to select patients in the various groups.

Antimicrobial agents used-

1. Metronidazole-Metronidazole and related nitroimidazoles are active in vitro against a wide variety of anaerobic protozoal parasites and anaerobic bacteria. Metronidazole is clinically effective in trichomoniasis, amebiasis, and giardiasis, as well as in a variety of infections caused by obligate anaerobic bacteria, including Bacteroides, Clostridium, and microaerophilic bacteria such as Helicobacter and Campylobacter spp.

2. Cefotaxime-Cephalosporins and cephamycins inhibit bacterial cell wall synthesis in a manner similar to that of penicillin. Cefotaxime, a Third generation cephalosporin is less active than first-generation agents against gram-positive cocci, but this is much more active against the Enterobacteriaceae, including b-lactamase-producing strains. A subset of thirdgeneration agents (ceftazidime and cefoperazone) also is active against $P$. aeruginosa but less active than other third-generation agents against gram-positive cocci.

3. Cefipime-Fourth-generation cephalosporins, such as cefepime, have an extended spectrum of activity compared with the third generation and have increased stability from hydrolysis by plasmid and chromosomally mediated b-lactamases. Fourthgeneration agents are particularly useful for the empirical treatment of serious infections in hospitalized patients when gram-positive microorganisms, Enterobacteriaceae, and Pseudomonas all are potential etiologies.

4. Sulbactum-Sulbactam is a b-lactamase inhibitor similar in structure to clavulanic acid. It may be given orally or parenterally along with a b-lactam antibiotic. It is available for intravenous or intramuscular use combined with Cephalosporins. Dosage must be adjusted for patients with impaired renal function. The combination has good activity against grampositive cocci, including b-lactamase-producing strains of $S$. aureus, gram-negative aerobes (but not Pseudomonas), and anaerobes; it also has been used 
effectively for the treatment of mixed intra-abdominal and pelvic infections.

5. Tazobactum-Tazobactam is a penicillanic acid sulfone b-lactamase inhibitor. In common with the other available inhibitors, it has poor activity against the inducible chromosomal b-lactamases of Enterobacteriaceae but has good activity against many of the plasmid b-lactamases, including some of the extended-spectrum class. It has been combined with piperacillin and Cefepime as a parenteral preparation.

6. Ofloxacin- It is a quinolone antibiotic.The quinolone antibiotics target bacterial DNA gyrase and topoisomerase IV. For many gram-positive bacteria (such as $S$. aureus), topoisomerase IV is the primary activity inhibited by the quinolones. In contrast, for many gram-negative bacteria (such as E. coli), DNA gyrase is the primary quinolone target. The fluoroquinolones are potent bactericidal agents against E. coli and various species of Salmonella, Shigella, Enterobacter, Campylobacter, and Neisseria. Minimal inhibitory concentrations of the fluoroquinolones for $90 \%$ of these strains $\left(\mathrm{MIC}_{90}\right)$ usually are less than $0.2 \mathrm{mg} / \mathrm{ml}$.

Ofloxacin and metronidazole were used in combination, whereas the cefotaxime was combined with sulbactum and cefepime was combined with tazobactum as the agents to be studied.

The operation time and other details were noted. Most of the surgeries were done by a particular surgeon.

Group 1 patients received a single dose of either Ofloxacin and Metronidazole at incision, and the group

\section{Results}

Over the period from sept 2010 to May 201139 patients of lap chole full filled with the inclusion criteria and taken for the study in two groups.

\section{Table 1: Study groups for lap chole}

\begin{tabular}{|l|l|l|l|l|}
\hline Treatment group & Nos. of Pts. & Median age & Males & Females \\
\hline Group1 & 20 & $35(29-62)$ & 9 & 11 \\
\hline Group 2 & 19 & $33(18-53)$ & 11 & 8 \\
\hline Total & $\mathbf{3 9}$ & $\mathbf{3 4}$ & $\mathbf{2 0}$ & $\mathbf{1 9}$ \\
\hline
\end{tabular}

2 patients received two more doses 8 hours apart. This policy was followed in open and laparoscopic groups separately.

A separate group received a fourth generation cephalosporin and tazobactum as a single dose prophylaxis only and the results were analysed.

While analysing the data information were segregated for cases undergoing in a combined Operation theatre where emergency cases are also undertaken and in operation theatres where only clean and elective cases are undertaken.

Data were analysed by SPSS 16.5 Statistical package. Graph and prism version 5.04 and excel 2007. RATES OF ssiwere extracted, $2 \times 2$ tables were prepared and odds ratio (OR), relative risk (RR)with $95 \%$ confidence interval $(95 \%$ CI) calculated. All categories were verified by chi-square test with $\mathrm{Y}$ ates correction (with $95 \% \mathrm{CI})$.

The economic cost analysis was analysed by using the following formula,

Economic analysis of the antibiotic prophylaxis= threshold cost/WITC

(WITC-Wound infection treatment cost)

Threshold cost (Antibiotics prophylaxis threshold cost) ABP-TC +NNT ABP cost

ABP (cost of antibiotics total)

NNT - 1/ absolute relative risk

Absolute relative risk- events occurred in control-events occurred in effective. 
Table 2: Study groups for lap chole

The two groups behave equally well and there were no SSI

\begin{tabular}{|l|l|l|}
\hline Treatment group & Nos. of Pts. & Nos. of SSI \\
\hline Group 1 & 20 & 0 \\
\hline Group 2 & 19 & 0 \\
\hline Total & $\mathbf{3 9}$ & $\mathbf{0}$ \\
\hline
\end{tabular}

Table 3: Wound infection rate in Lap chole in two groups

However the cost difference favoured the cefotaxim + sulbactum group, which was found to be significant.

In the second arm of open surgery 46 patients underwent elective abdominal surgeries (September 201-December 2010, by a single surgeon).

Table 4: Open surgery in two groups

\begin{tabular}{|l|l|l|l|l|}
\hline Groups (Open) & Nos. of Pts. & Median age & Males & Females \\
\hline Group 1 & 24 & 25 & 10 & 14 \\
\hline Group 2 & 22 & 45 & 9 & 11 \\
\hline Total & $\mathbf{4 6}$ & $\mathbf{3 5}$ & $\mathbf{1 9}$ & $\mathbf{2 5}$ \\
\hline
\end{tabular}

The rates of SSI is given in the table No significant difference was noted statistically.

Table 5: SSI rate in Open surgery

\begin{tabular}{|l|l|l|}
\hline Treatment groups & Nos. of Pts. & SSI \\
\hline Group 1 & 24 & $5(20 \%)$ \\
\hline Group 2 & 22 & $3(14 \%)$ \\
\hline Total & $\mathbf{4 6}$ & $\mathbf{8 ( 1 7 \% )}$ \\
\hline
\end{tabular}

In the other group single dose versus three doses of Ofloxacin and Metronidazole was studied. We had 32 patients. Here also no significant difference in SSI was noted.

Table 6: Single vs. Three doses of Ofloxacin+ Metronidazole groups

\begin{tabular}{|l|l|l|l|l|}
\hline Groups & Nos. of Pts. & Median age & Males & Females \\
\hline Group 1 & 15 & 37 & 4 & 11 \\
\hline Group 2 & 17 & 35 & 3 & 14 \\
\hline Total & $\mathbf{3 2}$ & $\mathbf{3 6}$ & $\mathbf{7}$ & $\mathbf{2 5}$ \\
\hline
\end{tabular}

Table 7: No significant difference of SSI rate between the two groups as in table 5

\begin{tabular}{|l|l|l|l|}
\hline Treatment groups & Total pts. & SSI & Total pts. \\
\hline Single dose & 15 & 4 & \\
\hline Three doses & 17 & 3 & \\
\hline Total & $\mathbf{3 2}$ & $\mathbf{7}$ & $\mathbf{3 9}(\mathbf{1 8 \%})$ \\
\hline
\end{tabular}

Now while comparing the rates of infection within these two combination regimes, no significant different in SSI were noted.

Table 8: No significant difference between the two groups

\begin{tabular}{|l|l|l|}
\hline Treatment groups & Total Patients & SSI \\
\hline Cefotaxime+Sulbactum & 47 & 8 \\
\hline Ofloxacin+Metronidazole & 32 & 7 \\
\hline Total & $\mathbf{7 9}$ & $\mathbf{1 5}$ \\
\hline
\end{tabular}


In the group who received only single dose of Cefipime and Tazobactum were analysed and no difference between the open and laparoscopic groups were noted.

Table 9: The cefipime + Tazobactum single dose group composition

\begin{tabular}{|l|l|l|l|l|}
\hline Surgery & Nos. Of Pts. & Males & Females & Median age \\
\hline Lap & 11 & 5 & 6 & 35 \\
\hline Open & 10 & 4 & 6 & 39 \\
\hline Total & 21 & 9 & 12 & 37 \\
\hline
\end{tabular}

Table 10: Cefipime+ Tazobactum single dose group SSI rates in the study

\begin{tabular}{|l|l|l|}
\hline Surgery & Nos. Of Pts. & SSI \\
\hline Lap & 11 & 0 \\
\hline Open & 10 & 2 \\
\hline Total & 21 & 2 \\
\hline
\end{tabular}

Cost analysis: The costs were calculated as per the price tags of the govt. Supply medications

1. Total cost of 20 cefotaxime and sulbactum was Rs. $14 x 20=$ Rs. 280

2. Total cost of 20 bottles of Ofloxacin and 20 vials of metronidazole was Rs. $22 x 20=$ Rs. 440.

3. Cefipime and tazobactum composition was procured from the market and was significantly more expensive.

This was a significant difference.

\section{Financial analysis}

Number needed to treat $=1 /$ control event rate-treatment event rate

Here single dose was considered against the three doses regime. So three doses regime was considered the control for the calculation of the NNT.

$\mathrm{NNT}=1 /(3 / 22)-(5 / 24)$

$\mathrm{NNT}=13$

For three dose cefotaxime and sulbactum

Economic analysis of antibiotic prophylaxis +threshold cost/ WITC

WITC $($ Wound infection treatment cost $($ Total $)=3 \times 142=$ Rs. 426

Threshold cost ABP-TC $=$ NNTx ABP $=$ RS.12012

For single dose Cefotaxime and sulbactum

Threshold cost $=$ Rs.4368

For Ofloxacin and metronidazole, for three doses the threshold cost was calculated to be Rs.6732 and for single dose regime, it was found to be Rs. 1982

\section{Discussion}

A sudy was undertaken in Germany to find out the efficacy of AMP in both open and laparoscopic cholecystectomies. It was found to be beneficial equally in both the open and laparoscopic groups over no AMP group and was found to be statistically significant $(\mathrm{p}=<05)[10]$.

Development of SSI leads to increase in hospital stay, Expenditures, Morbidity as well as deaths. [11,12].

Basing on NNIS report it can be sayed that SSI is an important nosocomial problem in all the countries. The world wide experience suggests that SSI is a major health care as well financial problems in all the countries $[13,14]$. 
Table 1: World wide experience of SSI

\begin{tabular}{|l|l|l|l|l|l|}
\hline Country & Setting & Period & Design & SSI No. & SSI (\%) \\
\hline Australia[15] & 28 Hospitals & 1992 & Retrospective & 5432 & 8 \\
\hline France[16] & $\begin{array}{l}\text { University } \\
\text { Hospital }\end{array}$ & $1993-1998$ & Retrospective & 9422 & 7 \\
\hline US of A[17] & NNIS Hospitals & $1992-1998$ & Prospective & 738398 & 3 \\
\hline Thailand[18] & $\begin{array}{l}\text { University } \\
\text { Hospital }\end{array}$ & $2003-2004$ & Prospective & 4764 & 1 \\
\hline Vietnam17] & $\begin{array}{l}\text { Tertiary care } \\
\text { Hospitals }\end{array}$ & $1992-1998$ & Prospective & 697 & 11 \\
\hline Italy[18] & $\begin{array}{l}\text { Public } \\
\text { Hospitals(31) }\end{array}$ & 1 month & Prospective & 617 & 3 \\
\hline
\end{tabular}

SSI can be caused by two different kinds of spreads. Most common cause of exogenous route is the Operating environment and the most common endogenous route is from the GIT or Genital tract in females.

The environmental factors are tackled by standard operation theatre conditions as well as regular srveilence by the team of microbiologists as well as the preoperative preparation for surgery and are dependent on the institutional philosophy. Control of endogenous infection is best tackled by Preoperative use of antibiotics.

It is well established that Prophylactic antibiotics must be injected at anaesthesia and it has been shown that multiple doses regime is redundant for preventing SSI. It is also shown that antibiotics given over two hours preoperatively failed to initiate desired effect and action.

Keeping these factors in mind the study was undertaken to evaluate the best and most economic prophylactic antibiotics regime in two different environments. One, in which both emergency as well as elective abdominal cases are undertaken, the second is where only elective cases are undertaken. The reason being, such conditions exist in the state of Assam. Both laparoscopic as well as open elective cases were considered $t$ find out if any difference would come out after the study.

\section{Conclusion}

The study conclusively states that single dose of prophylactic antibiotics is good enough for laparoscopic as well as open surgeries when done in elective only operation theatres.
Open abdominal elective surgeries performed in a combined operation theatres, where both emergency and elective cases are undertaken need three doses.

Laparoscopic surgeries done in combined operation theatres do not need more than single dose prophylaxis. All the regimens, used properly, are equally efficacious in preventing SSI. A single dose of Cefotaxime and sulbactum is the most cost effective surgical prophylaxis for SSI.

\section{Abbreviations used}

$\begin{array}{lll}\text { 1. } & \text { AMP- } & \text { Antimicrobial prophylaxis } \\ \text { 2. } & \text { ARR- } & \text { Absolute relative risk } \\ \text { 3. } & \text { CI- } & \text { Confidence interval } \\ \text { 4. } & \text { DOS- } & \text { Duration of Surgery } \\ \text { 5. } & \text { LOS- } & \text { Length of surgery } \\ \text { 6. } & \text { LC- } & \text { Laparoscopic cholecystectomy } \\ \text { 7. } & \text { MIC- } & \text { Minimum inhibitory concentration } \\ \text { 8. } & \text { NNIS- } & \text { National nosocomial infection } \\ & \text { surveillance } & \\ \text { 9. } & \text { OR- } & \text { Odd ratio } \\ \text { 10. } & \text { PA- } & \text { Prophylactic antibiotics } \\ \text { 11. } & \text { RR- } & \text { Relative risk } \\ \text { 12. } & \text { SSI- } & \text { Surgical site infection }\end{array}$

Funding: Nil, Conflict of interest: None. Permission of IRB: Yes

\section{References}

1. Alicia $\mathbf{J}$ et al. Guidelines for prevention of surgical site infection. American Journal of Infection Control 1999 April; 27:100

2. Auerbach AD. Prevention of Surgical Site infection. Agency for healthcare Research and Quality 2001:22144 
3. Nigel Mark Bagnall et al. Surgical site infection. Surgery, 1991;27(10):426-30

4. Mangram AJ et al. Guideline for prevention of Surgical site infection, Infect Control Hosp Epidemiol 199;20:247-80

5. Mandell GL et al,Douglas and Bennett's Principles and practice of infectious diseases. $6^{\text {th }}$. EditionNew York:Elsevier/Churchill Livingstone, 2005

6. Dellinger EP, Gross PA, Barrett TL et al. Quality standard for antimicrobial prophylaxis in surgical procedures. Infectious Diseases Society of America. Clin Infect Dis. 1994 Mar;18(3):422-7.

7. Page CP, Bohnen JM, Fletcher JR, McManus AT, Solomkin JS, Wittmann DH. Antimicrobial prophylaxis for surgical wounds. Guidelines for clinical care. Arch Surg. 1993 Jan;128(1):79-88.

8. Meijer WS, Schmitz PI, Jeekel J. Meta-analysis of randomized, controlled clinical trials of antibiotic prophylaxis in biliary tract surgery. Br J Surg. 1990 Mar;77(3):283-90.

9. DiPiro JT, Cheung RP, Bowden TA Jr, Mansberger JA. Single dose systemic antibiotic prophylaxis of surgical wound infections. Am J Surg. 1986 Nov;152(5):552-9.

10. Platell C, Hall JC. The prevention of wound infection in patients undergoing colorectal surgery. $\mathrm{J}$ Hosp Infect. 2001 Dec;49(4):233-8.

11. Dimick JB, Chen SL, Taheri PA, Henderson WG, Khuri SF, Campbell DA Jr. Hospital costs associated with surgical complications:

a report from the privatesector National SurgicalQuality Improvement Program. J Am Coll Surg. 2004 Oct;199(4):531-7.

12. Kirkland KB, Briggs JP, Trivette SL, Wilkinson WE, Sexton DJ. The impact of surgical-site infections in the 1990s: attributable mortality, excess length of hospitalization, and extra costs. Infect Control Hosp Epidemiol. 1999 Nov;20(11):725-30.

13. Fiona Burton. Preventing surgical site infections. Wound essentials 2007;2:124-31

14. Coello $\mathrm{R}$ et al. Adverse impact of surgical site infections in English hospitals. Journal of hospital infection 2005;60:93-103

15. Kable AK, Gibberd RW, Spigelman AD. Adverse events in surgical patients in Australia. Int $\mathbf{J}$ Qual Health Care. 2002 Aug;14(4):269-76.

16. Rioux C, Grandbastien B, Astagneau P. The standardized incidence ratio as a reliable tool for surgical site infection surveillance. Infect Control Hosp Epidemiol. 2006 Aug;27(8):817-24. Epub 2006 Jul 24.

17. Nguyen D, MacLeod WB, Phung DC, Cong QT, Nguy VH, Van Nguyen H, Hamer DH. Incidence and predictors of surgical-site infections in Vietnam. Infect Control Hosp Epidemiol. 2001 Aug;22(8):48592.

18. Moro ML, Morsillo F, Tangenti M, Mongardi M, Pirazzini MC, Ragni P; ICN Regional Group. Rates of surgical-site infection: an international comparison. Infect Control Hosp Epidemiol. 2005 May;26(5):442-8.

\section{How to cite this article?}

Ganguly NN, Ray RP, Lahkar M, Siddiqui A. A prospective study to find out the most cost effective preoperative prophylactic antibiotic regime in elective abdominal routine surgeries. Int J Med Res Rev 2016;4(2):157-163. doi: 10.17511/ijmrr.2016.i02.006. 